\section{History of Paediatrics}

\section{G127 'THE CHILD IS FATHER TO THE MAN'. THE RELATIONSHIP BETWEEN CHILD HEALTH AND ADULT MORTALITY IN THE 19TH AND 20TH CENTURIES}

B. Harris. Southampton University, UK

This paper examines the relationship between recent work on the role of 'life-course events' on adult mortality and historical research into trends in height and mortality. The paper focuses on an article by Kermack, McKendrick and McKinley which appeared in the Lancet in 1934. Kermack, McKendrick and McKinley argued that it was easier to understand the pattern of mortality decline in England and Wales in the late-19th and early-20th centuries if one thought in terms of the experience of particular cohorts, rather than concentrating exclusively on what one might call 'period effects'.

The paper will examine the impact of this article on subsequent work in the field of anthropometric history, including the work of Fogel and Costa in the United States, and Floud, Wachter and Gregory in the UK.

\section{G128 SIR JAMES SPENCE, PIONEER OF BRITISH PAEDIATRICS}

A. Craft. Department of Child Health, Sir Fames Spence Institute, Newcastle, $U K$

Spence was born in 1892 at a time when paediatrics as a specialty had yet to be born. Undistinguished as an undergraduate, he went on to be one of the leaders of the emerging paediatric discipline and was one of the inspirations behind the formation of the B.P.A, the forerunner of the RCPCH. He is best known for his innovative approaches to the care of children in hospital and in particular that mothers could be an asset when their babies were admitted and should be allowed to "room in". One of his great strengths was that there could be no progress without scientific study, the topic of a lecture given in 1953 "The methodology of clinical science". Prior to World War II he was commissioned by the City of Newcastle to undertake a study to determine why the infant mortality rate was so high. This eventually led to the Thousand Families one of the first longitudinal cohort studies with its participants having recently been followed up at the age of 50 years. He was deeply affected by his participation in the First World War where he distinguished himself and was awarded the MC and bar. After the war many prospective paediatricians from not only the UK but elsewhere were to be found working with him in Newcastle. He travelled widely and was instrumental in establishing the Australian College of Paediatrics. He died prematurely in 1954 but his important work, and disciples, lived on to greatly influence paediatrics over the next generation. He was a scientist and philosopher but above all he was an inspirational teacher. He was accepted by his contemporaries as a wise counsellor, moderate in the presentation of his views but nevertheless a practical minded visionary. His whimsical charm made him a most attractive personality.

\section{G129 BREAST IS BEST? INFANT FEEDING IN THE FOUNDLING HOSPITALS OF LONDON AND FLORENCE IN THE 1740s}

A. Levene. University of Cambridge, UK

In the 18th century, the merits of the mother's milk were not clearly understood, and many women sent their children away to be nursed. Infants abandoned to the London Foundling Hospital or the Spedale degl'Innocenti in Florence, faced a yet more ambiguous situation: was it better to send them to be breast fed by a paid nurse who might neglect them, or convey 'undesirable characteristics' to the child though her milk; or to use artificial feeding methods? The director of the Innocenti in 1742, faced with high mortality rates among foundlings, turned to an eminent Florentine doctor, Antonio Cocchi, to ask his opinion on the effects of dry nursing on infants. The answer was almost entirely in favour of the practice, in sharp contrast to the policy adopted by the contemporary governors of the London Foundling Hospital. There, dry nursing had been found to raise the risk of death for infants, and as was stated in a letter on the subject to the Innocenti, wet nursing had been almost universally adopted as standard practice.

I will consider the reasons for these different views on infant feeding in two contemporaneous institutions for abandoned children. I will also look at whether artificial feeding was actually adopted at the Innocenti, and the consequences for infant survival.

\section{G130 THE HISTORY OF DIAGNOSTIC SCREENING FOR CONGENITAL DISLOCATION OF THE HIPS (CDH)}

P.M. Dunn. University of Bristol, Division of Child Health, Southmead Hospital, Bristol BS10 5NB, UK

Hippocrates for the first to describe $\mathrm{CDH}$. Two thousand years later, Ambroise Paré (1575) added to our knowledge. But it was Guillaume Dupruytren (1847) who provided the first classic description of the condition, its aetiology and presentation. In 1879 Wilhelm Rosser described neonatal hip instability and suggested the need for early detection and treatment. Pierre Le Damany, a surgeon in Brittany, was the first clinically to screen a cohort of newborn infants (1912). In 1933 Vittorio Putti proposed that all newborn infants should be screened radiologically for $\mathrm{CDH}$ at birth using the technique of Hilgenreiner (1925). Marino Ortolani, a paediatrician in Ferrara, described his clinical test for $\mathrm{CDH}$ in 1948. This manoeuvre was improved by the addition of the provocation test of Kurt Palmén (1953) and Thomas Barlow (1962). A neonatal screening programme was introduced in the UK in 1969; it was subsequently updated in 1986. Ultrasound examination of the neonatal hip, pioneered by $\mathrm{R}$. Graf in 1984, has been used as a screening tool for high-risk infants. Currently the outcome of clinical screening in the UK varies from poor to excellent depending on the organisation and efficiency of the local programme. 